\title{
Bacterial Resistance to Antibiotics and Implanted Medical Device
}

\section{Sompop Bencharit*}

Department of Prosthodontics, School of Dentistry and Department of Pharmacology, School of Medicine, University of North Carolina at Chapel Hill, Chapel Hill, NC 27599, USA

\section{Editorial}

In 1928, Alexander Fleming discovered penicillin and since the early 1940s, antibiotics have saved millions of lives. It was however estimated that about $50 \%$ of antibiotics prescribed nowadays are unnecessary [1]. The majority of clinicians and patients pay little attention to the adverse effect from misuse and abuse of antibiotics. In addition, we use common antibiotics, such as amoxicillin, clindamycin, etc., in routine laboratory experiments. Antibiotic resistance of bacteria is commonly used in gene cloning. In addition to clinical and laboratory use, antibiotics are used in slowing bacterial growth in meat products in the meat industry. Extensive use of common antibiotics can theoretically lead to bacterial resistance known as super bugs. This problem can not only affect individual patients but may also become a wide-spread public health crisis.

There are only a handful of antibiotics used in dentistry. As a dental specialist, I personally only prescribe the use of antibiotics in cases with an acute infection or an extensive surgical procedure. Like most clinicians, I did not see any adverse effects from antibiotics in the majority of my patients. However, a few months ago, a patient of mine received an extensive bone grafting and dental implant procedure, clindamycin was used since she was allergic to penicillin. While the use of clindamycin is deemed to be completely safe and the adverse effect is believed to be rare [2], the patient developed a Clostridium difficile or C. diff infection. She had to spend almost a week in the hospital. Looking back to this case, I learned to be more careful with prescribing any antibiotics, especially the broad spectrum antibiotics. I also routinely inform patients of the possible side-effects of antibiotics and what he/she could do to prevent them.

Use of broad spectrum antibiotics should not be used preventatively, but empirically for immediate control of an acute serious infection, super infection (multiple bacterial infection), and in cases of bacterial resistance from narrow-spectrum antibiotics. Overuse of penicillin and its derivatives in the past may have contributed to the more recent rise in number of patients allergic to narrow spectrum penicillin derivatives, and the increased incidence of bacterial resistance to these narrow spectrum antibiotics. This may consequently increase use of broad spectrum antibiotics and, therefore, the incidence of complications from them such as $C$. diff. There is clearly a need for developing a new strategy to combat infection with antibiotics.

There are two keys in the strategy to prevent the development of antibiotic resistant bacteria. Public awareness campaigns for appropriate prescription and use of antibiotics are constantly needed. The development of new antibiotics and the improvement of current antibiotics have to go hand-in-hand. However, in recent years, new antibiotics development is slowing down so much that we cannot really rely on the creation of new antibiotics alone (http://www.cdc.gov/Features/AntibioticResistance/charts.html\#map). Improving current antibiotics as well as alternative strategies for prevention of infection is increasing its importance.

Some chronic localized infections can theoretically facilitate the bacterial resistance to antibiotics. Advances in implanted medical de- vices including orthopedic implants, dental implants, urinary catheters, prosthetic heart valves, etc. can provide a safe harbor for certain bacterial species. These bacteria species can mutually exist on the surface of the implanted device through the process of biofilm formation. Interestingly, the bacterial community in the biofilm can develop resistance to antibiotics without canonical mechanisms of antibiotic resistance, such as efflux pumps, modifying enzymes, and target mutations [3]. Biofilm formation in chronic diseases such as cystic fibrosis was believed to be the main cause for bacterial resistance to antibiotics [4]. Biofilm-specific bacterial genes such as ndvB in Pseudomonas aeruginosa can be used as a novel drug target [5]. Understanding biofilm formation using a combination of genomic, proteomic, and microbiomic approaches and developing implant materials resistant to biofilm may be the key to prevent serious future development of bacterial antibiotic resistance through implanted medical devices. In addition, there should also be an emphasis on reducing biofilm formation as an effective maintenance of implanted medical devices.

\section{References}

1. Wise R, Hart T, Cars O, Streulens M, Helmuth R, et al. (1998) Antimicrobial resistance. Is a major threat to public health. BMJ 317: 609-610.

2. Mazur N, Greenberger PA, Regalado J (1999) Clindamycin hypersensitivity appears to be rare. Ann Allergy Asthma Immunol 82: 443-445.

3. Stewart PS, Costerton JW (2001) Antibiotic resistance of bacteria in biofilms Lancet 358: 135-138.

4. Drenkard E, Ausubel FM (2002) Pseudomonas biofilm formation and antibiotic resistance are linked to phenotypic variation. Nature 416: 740-743.

5. Beaudoin T, Zhang L, Hinz AJ, Parr CJ, Mah TF (2012) The Biofilm-Specific Antibiotic Resistance Gene ndvB Is Important for Expression of Ethanol Oxidation Genes in Pseudomonas aeruginosa Biofilms. J Bacteriol 194: 3128 3136.

${ }^{*}$ Corresponding author: Sompop Bencharit, Department of Prosthodontics, School of Dentistry, Department of Pharmacology, School of Medicine, University of North Carolina at Chapel Hill, CB\#7450, Chapel Hill, NC 27599-7450, USA, E-mail: Sompop_Bencharit@dentistry.unc.edu

Received June 22, 2012; Accepted June 25, 2012; Published June 26, 2012

Citation: Bencharit S (2012) Bacterial Resistance to Antibiotics and Implanted Medical Device. Adv Pharmacoepidem Drug Safety 1:e112. doi:10.4172/2167-1052.1000e112

Copyright: @ 2012 Bencharit S. This is an open-access article distributed under the terms of the Creative Commons Attribution License, which permits unrestricted use, distribution, and reproduction in any medium, provided the original author and source are credited. 